\title{
Women's Participation in Natural Disasters and Accidents: A Case Study of Bam Earthquake, Iran
}

\author{
Mahmoud Nekoei Moghadam¹, Zahra Afshar Hossein Abadi ${ }^{*}$, Ali Ardalan ${ }^{3}$, Somayeh Aminizadeh $^{4}$ \\ 1. Department of Management, Faculty of Management and Information, Kerman University of Medical Sciences, Kerman, Iran. \\ 2. Department of Human Science, Faculty of Urban Management, Ferdowsi University of Mashhad, Mashhad, Iran. \\ 3. Department of Health, Faculty of Health in Disaster, Tehran University of Medical Sciences, Tehran, Iran. \\ 4. Department of Community Health, Faculty of Medicine and Health Science,Universiti Putra Malaysia, Selangor, Malaysia.
}

Citation: Nekoei Moghadam M, Afshar Hossein Abadi Z, Ardalan A, Aminizadeh S. Women's Participation in Natural Disasters and Accidents: A Case Study of Bam Earthquake, Iran. Health in Emergencies and Disasters Quarterly. 2016; 1(4): 201-208. https://doi.org/10.18869/nrip.hdq.1.4.201

: https://doi.org/10.18869/nrip.hdq.1.4.201

Article info:

Received: 10 Feb. 2016

Accepted: 30 May 2016

\section{Keywords:}

Natural disasters and accidents, Women, Cooperation

\section{ABSTRACT}

Background: Although natural disasters leave thousands of deaths and wounded, one of their most significant outcomes is empowering women as well as taking measures with special attention to women. This study aimed to analyze women's cooperation and its affective factors in natural disasters and accidents.

Materials and Methods: The study design is cross-sectional and descriptive. The study population comprised the women living in Bam, Iran and the sample size was calculated as 385 . The study instrument is a researcher-made questionnaire. To analyze the data, the descriptive statistical methods, the statistical correlation test, and 1-way analysis of variance were performed by using SPSS 16.

Results: The study result about the effects of the women demographic characteristics on their cooperation showed that there were no relationships between women's cooperation and their marital status or degree of education. However, there were significant and positive relationships between their cooperation and variables of age, being indigenous, and occupational status. The results have also indicated that there were significant relationships between women's cooperation and variables of knowledge and attitude.

Conclusion: Women, despite their vulnerability in natural accidents, have the capability in performing different tasks such as taking care and accommodating the injured family members, and making peace and relief in difficult and undesirable situations after natural disasters such as earthquake. However, the results of this study revealed that women's cooperation in different parts of crisis management was very limited. This matter demands more attention of the responsible authorities.

\footnotetext{
* Corresponding Author: 


\section{Introduction}

$\mathbf{T}$

oday, numerous studies have shown that in planning for acquiring the preparedness against disasters, the role of people as one of the most important and largest group among the beneficiary groups has been often neglected [1]. According to the official statistics, more than half of the Iran's 70 million population are women [2]. However, the Iranian women's participation in many social activities, including crisis management compared to other developing countries is very low [3]. Clipatrick et al. believed that neglecting role of women in disasters, on one hand, was due to the patriarchal attitudes toward women, and on the other hand, due to authorities and the professionals' view toward disasters [4].

According to the International Labor Organization, one of the important obstacles for women's participation in crises is unsafe environment for their participation. In many cases, female aid workers cannot share their needs and problems with their male counterparts [5]. Also because of women's vulnerability to some pressures resulted from the accidents, they suffer from a lot of worldwide mental harms and problems [6]. Despite their vulnerability, women could perform numerous activities, including caring family, sheltering, providing relief, and other similar things in unpleasant conditions after natural disasters such as earthquake, flood, drought and storms. They can effectively prepare the society to deal with the crisis [7].

Around the world, women employ different strategies for their self-empowerment, ranging from participation in government official programs or local and regional programs and through informal networks and organizations [8]. Other studies have also shown that women are faster in searching information related to dangers and how to help and prepare in crises. They are also more willing to inform the public about the dangers [9]. Various studies have been conducted on the role of women in natural disasters and crises. In a study conducted in Turkey after the earthquake on March 13, 1990, it was found that stress and anxiety in women were far more than men. The study results have emphasized the necessity of the education for disaster preparedness activities in women [10]. Ive Krishna in a study found that women could play important roles in government policies and informal education programs to raise awareness among the community members. They could also form organizations for crisis management operations [11].

In a qualitative study conducted in 2009 in the state of New Kharab India, researchers concluded that poli- cies and strategies to engage more women in decisionmaking bodies, leadership trainings to increase their awareness of their rights, and promoting their skills were among the important factors related to women's participation [12]. Parsi Zadeh and Fallahi study on the women community after March 1997 earthquake showed that women were often involved in saving lives, but despite an intense desire, they were not so influential and helpful owning to their lack of knowledge of safety rules [13].

Sharifi (2004) has also pointed to the importance of the presence and the activities of Sisters' Basij organization in Bam earthquake. These activities comprised visiting the survivals' tents, obtaining and collecting reports of problems in the earthquake zone and reflecting them to the relevant authorities as well as sending staff to supervise hospitals by aid workers [14]. In Ardalan and Tieman (2007) study, it was reported that involvement of women in all activities and programs, including decision-making, policy-making, management, programs, and emergencies were appropriate strategies for participating women. The most important actions in this regard were plans to reduce the inequalities in accessing resources, opportunities, knowledge, empowerments, equipping groups, and increasing capabilities of the involved organizations [15]. Ostovar Khah has also mentioned some reasons of low women's participation such as inequality of women in education before the crisis, their indifference to the problems, and unequal participation in important decision-making activities [16].

With regard to limited field research on the factors affecting women's participation in the accidents and disasters, we examined a number of studies in this topic. The result of Yazdanpanah and Samadian research (2008) on the social participation of women in Kerman showed that about $22.7 \%$ of women had a positive attitude, $11.1 \%$ a negative attitude, and $23 \%$ had an indifferent attitude toward social participation [17]. Also, $76.5 \%$ of them told that they had no knowledge of cooperative organizations. In Vosoughih and Yousefi Aghabin study (2005) on women's demographic characteristics and attitudes to social cooperation, the results showed a significant relationship between the women's attitude about themselves, age, educational level, and social cooperation [18].

Safiri study (2006) on the effects of education on women's cooperation showed that academic education had no effects on their social cooperation. The results of Kordi study on the factors affecting the women's attitude and their social cooperation in Golestan Province showed that there was no relationship between the variables of age and marital status of the women and their cooperation [20]. 
In a study by Ghaderzadeh and Yousefvand on the relationship between the women's demographic characteristics and their cooperation, it was found that there was a significant relationship between the women's social cooperation and variables of marital status and age [21]. Similarly, in another study which was about the women's social cooperation in Mianeh City, Iran, different factors, including marital status, occupation, age, sexism, patriarchy, deprivation, traditionalism, and education were investigated which showed a significant relationship between women's social cooperation and the variables of occupation and marital status [22].

With regard to many natural and even man-made disasters in Kerman Province (such as earthquake and its damages that have always threatened this area), and also because of the limited research on the subject of women's role in natural disasters, it seems that investigating this subject is of high importance. Therefore, this study aimed to investigate the participation of women in accidents and natural disasters and the factors affecting it.

\section{Materials and Methods}

The cross-sectional study is an applied research and its methodology is descriptive analysis. To analyze women's cooperation and its influential factors in natural disasters and accidents, a researcher-made questionnaire was designed by using the related literature and other studies. It included four parts:

- Participants' demographics characteristics (questions from 1-9),

- Knowledge ( questions from 10-14),

- Attitude (questions from 15-21), and

- Cooperation (questions from 22-32).

All answers were scored in Likert-type scale from "very much" to "very little" (very much: 5, very: 4, average: 3 , little: 2 , and very little: 1 ). The validity of this questionnaire was approved by the content validity and the experts' opinions and its reliability was also tested on 30 people and test-retest that the computed correlation coefficient of 0.88 showed the reliability of the questionnaire. The study setting was Bam City. Since the earthquake happened in this city 10 years ago and the population must include samples that were able to help at the time of the earthquake, the study population comprised women who were more than 35 years old. Their number was about 13602 people and by using the Cochran formula, the sample size was estimated as 385 people. The random sampling method was used to distribute the questionnaires. The Cochran formula and its calculation are presented below.

$$
\begin{aligned}
& t=1.96 \\
& p=0.48 \\
& q=0.52 \\
& N=13602 \\
& n=\frac{\frac{t^{2} p q}{d^{2}}}{1+\frac{1}{N}\left(\frac{t^{2} p q}{d^{2}}\right)}=\frac{\frac{1.96^{2} \times 0.48 \times 0521}{0.05^{2}}}{1+\frac{1}{13602}\left(\frac{1.96^{2} \times 0.48 \times 0.52}{0.05^{2}}-1\right)}=385
\end{aligned}
$$

To analyze the relationships between the variables, descriptive statistics and independent samples t test, ANOVA, correlation, and regression tests were performed by using SPSS 16.

The research hypotheses are as follows:

- Women's cooperation in the natural disasters and accidents is low.

- Women's demographic characteristics (marital status, age, occupation, being indigenous, and education) affect their cooperation in natural disasters and accidents.

- Women's knowledge and awareness affect their cooperation in natural disasters and accidents.

- Women's attitude affects their cooperation in natural disasters and accidents.

\section{Results}

The study responders were women more than 35 years old living in Bam who $77 \%$ of them were $35-45$ years old, $16.7 \% 45-55$ years and $6 \%$ were more than 55 years old. About $90 \%$ of them were indigenous to Bam and $10 \%$ from other cities. With regard to their marital status, $80.5 \%$ were married and $19.5 \%$ single. The education degree of most responders was diploma and associate degree (42.5\%) and the others had bachelor's and master's degree (42.5\%), high school diploma (19.8\%), and $\mathrm{PhD}(0.6 \%)$. Most responders were housewives (39.2\%), and about $37.8 \%$ of them had governmental jobs and others were retired or unemployed educated ones (23\%). The results of women's cooperation in natural disasters and accidents showed that $53 \%$ of these people had low, $43.8 \%$ average, and 3.2\% 
Table 1. Mean and standard deviation of participation, knowledge, and attitude scores.

\begin{tabular}{|c|c|c|}
\hline Variable & Mean & SD \\
\hline \multicolumn{3}{|l|}{ Cooperation } \\
\hline Participation on educating crisis programs & 2.61 & 2.48 \\
\hline Participation in rescue activities during earthquake & 2.55 & 1.13 \\
\hline Participation in activities such as camp management & 2.05 & 1.00 \\
\hline Participation in disease control activities after the earthquake & 2.60 & 1.99 \\
\hline Participation in sanitation and health activities after the earthquake & 2.77 & 1.98 \\
\hline Participation in activities such as post-crisis reconstruction of damaged houses & 2.32 & 1.07 \\
\hline Participation in support groups and NGOs after the earthquake & 2.49 & 1.21 \\
\hline Participation in the rehabilitation of refugees after the earthquake & 2.44 & 1.18 \\
\hline Participation in administrative activities such as decision-making at times of crisis & 2.59 & 2.54 \\
\hline \multicolumn{3}{|l|}{ Knowledge } \\
\hline Knowing self-rights as a woman & 3.20 & 0.92 \\
\hline Familiarity with relevant organizations of women's affairs & 2.93 & 0.93 \\
\hline Knowledge of different kinds of participations & 3.08 & 1.36 \\
\hline Knowledge about treatment and rescue in accidents and natural disasters & 3.27 & 2.55 \\
\hline Knowledge about first aid at accidents and disasters & 3.09 & 0.86 \\
\hline \multicolumn{3}{|l|}{ Attitudes } \\
\hline $\begin{array}{l}\text { The believe in being emotional as a barrier to women's participation in events and } \\
\text { natural disasters }\end{array}$ & 2.95 & 1.12 \\
\hline $\begin{array}{c}\text { The believe in higher share of men in crisis management activities as a barrier to } \\
\text { women's participation in events and natural disasters }\end{array}$ & 3.08 & 1.96 \\
\hline The believe in women minority as an obstacle for women cooperation & 3.15 & 1.15 \\
\hline $\begin{array}{l}\text { Conflict and crisis management activities to address issues related to family and } \\
\text { children }\end{array}$ & 3.70 & 2.93 \\
\hline $\begin{array}{c}\text { The lack of using results and research on women's cooperation in crisis management } \\
\text { plans }\end{array}$ & 3.14 & 2.46 \\
\hline $\begin{array}{l}\text { The believe in not handing over implementation of crisis management plans and } \\
\text { programs to women as a motive for women's participation in events and natural } \\
\text { disasters }\end{array}$ & 3.43 & 1.13 \\
\hline $\begin{array}{l}\text { The believe in the lack of senior executives support as a motivating factor for the } \\
\text { more presence of women in events and natural disasters }\end{array}$ & 3.57 & 3.29 \\
\hline
\end{tabular}

high cooperation. The findings on the knowledge of the people had also shown that about $53.7 \%$ of them had weak, $46 \%$ average, and $0.3 \%$ desirable knowledge. With regard to their attitude, $66 \%$ of them had low, $31 \%$ average, and $3 \%$ desirable attitude toward cooperation (Table 1). 
Table 2. Independent sample t test results to determine the relationship between cooperation and variables of marital status and being indigenous.

\begin{tabular}{|c|c|c|c|c|c|c|}
\hline \multicolumn{2}{|c|}{ Variables } & Mean & SD & df & $t$ & Level of Significance \\
\hline \multirow{2}{*}{ Marital status } & Single & 21.19 & 8.88 & \multirow{2}{*}{85.15} & \multirow{2}{*}{1.43} & \multirow{2}{*}{0.15} \\
\hline & Married & 27.6 & 6.70 & & & \\
\hline \multirow{2}{*}{ Indigenous status } & Indigenous & 20.21 & 6.98 & \multirow{2}{*}{88.97} & \multirow{2}{*}{1.96} & \multirow{2}{*}{0.05} \\
\hline & Not indigenous & 18.10 & 7.92 & & & \\
\hline
\end{tabular}

Table 3. The results of the ANOVA test to analyze the relationship between cooperation level and variables of age, occupational status, and education.

\begin{tabular}{ccccccc}
\hline $\begin{array}{c}\text { Cooperation } \\
\text { Variables }\end{array}$ & Mean & SD & Sum of Squares & df & F & $\begin{array}{c}\text { Level of the } \\
\text { Significance }\end{array}$ \\
\hline Age & 19.83 & 7.20 & 17685.500 & 341 & 4.066 & 0.01 \\
Occupation & 19.86 & 7.26 & 17714.991 & 336 & 4.153 & 0.003 \\
Education & 19.77 & 7.19 & 176464.358 & 337 & 0.97 & 4.24 \\
\hline
\end{tabular}

To analyze women's cooperation based on the marital status, and also being indigenous, the Independent sample t test was used. The obtained results showed no significant difference between the single and married people $(\mathrm{P}=0.15)$. But there is a significant relationship between being indigenous and cooperation and the degree of cooperation of the indigenous people was more than those who were not $(\mathrm{P}=0.05)$ (Table 2$)$.

We used 1-way ANOVA to analyze the age, occupational status, and academic education (Table 3). To analyze the relationship between age and women' cooperation, the participants were at first divided into three age groups:

- Group one: 35-45 years old

- Group two: 46-55 years old

- Group three: more than 55 years old

The results showed that the level of the significance was 0.01 (less than the significance level of 0.05 ) which indicated the statistical significance between the groups. Post comparisons using Tukey test showed that the mean score for group one $(\mathrm{M}=19.41$ and $\mathrm{SD}=7.26)$ was significantly different from that of group three $(M=24.05$ and $\mathrm{SD}=7.89$ ). About the level of the education, the results indicate no significant difference between the level of education and people's cooperation ( $\mathrm{P}=4.24)$. The results of ANOVA to examine the relationship between employment and participation rates showed a significance relationship between the people's cooperation and occupational status $(\mathrm{P}=0.003)$. Tukey test also showed that there was difference between the groups of housewives $(\mathrm{M}=18.71, \mathrm{SD}=6.97)$ and employed ones $(\mathrm{M}=21.75$, $\mathrm{SD}=7.25)$ and also between the educated unemployed people $(\mathrm{M}=17.81, \mathrm{SD}=7.849)$ and the employed ones $(\mathrm{M}=21.75, \mathrm{SD}=7.25)$.

To analyze the relationship between the variables of knowledge and the attitude with people's cooperation, the Pearson correlation coefficient test was used. As the results in Table 4 shows, there is a significant relationship between

Table 4. The correlation between knowledge and attitude with the participation.

\begin{tabular}{|c|c|c|}
\hline Variables & The Pearson Correlation Coefficient & Level of Significance \\
\hline Knowledge & 0.392 & 0.000 \\
\hline Attitude & 0.44 & 0.000 \\
\hline
\end{tabular}


Table 5. The results of stepwise linear regression, the dependent variable and independent variables involved.

\begin{tabular}{cccc}
\hline Model & The Coefficient of Determination & F Statistic & P \\
\hline 1 & 1.72 & 78.49 & 0.00 \\
2 & 0.57 & 50.98 & 0.00 \\
\hline & & $\begin{array}{c}\text { IHealth in } \\
\text { Emergencies and [D]isasters [Oluarterly }\end{array}$
\end{tabular}

Table 6. The results of stepwise linear regression coefficients obtained from the participation with independent variables.

\begin{tabular}{ccccc}
\hline Model & Variables & Variable Coefficient & T Statistic & P \\
\hline 1 & Attitude & 0.44 & 8.86 & 0.00 \\
2 & Attitude & 0.34 & 6.42 & 0.00 \\
& Knowledge & 0.23 & 4.35 & 0.00 \\
\hline
\end{tabular}

the attitude and the knowledge of women with their level of cooperation. To determine which variables, knowledge or attitude, is a stronger predictor for cooperation, the stepwise linear regression test was used (Tables 5 and 6). As Table 6 shows, people's attitude is a stronger predictor than their knowledge with regard to their cooperation.

\section{Discussion}

Since women comprise half of our society, their presence in all areas, and especially in disasters (which is one of the main concerns of the authorities and people of each country), can reduce the dangers and prevent many irreparable damages. The results have shown that 52.9\% of women have low, $43.8 \%$ average, and 3.2\% high participation in disasters, and therefore, the first hypothesis got confirmed. Regarding the women's presence in an event such as Bam earthquake, it can be said that they were more active in programs such as environment health and hygiene, disease control, and in general postearthquake activities and did not have much activities in prevention programs.

This inactivity can be due to women's absence in social cooperation activities and lack of crisis management preparation programs for women. About $76.5 \%$ of women also did not have any information about women activities' organizations. With regard to the relationship between women's participation and demographic characteristics, the results indicated no relationship between marital status and women's cooperation, but there was a significant relationship between being indigenous and cooperation and the level of cooperation of indigenous people was more than those who were not. There was also a relationship between age and the level of cooperation. Ghaderzadeh and Yousefvand (2011) have reported that there was a significant association between variables of marital status and age with the women's social cooperation. The results showed no relationship between the level of the education and the cooperation.

Safiri study (2006) also showed that the academic education did not have any effect on the social cooperation of women. The results regarding the occupational status and the level of the education showed a strong and significant relationship between occupational status and the level of the women's cooperation. Ghorayshi, Alizadeh, and Ebrahimi (2012) have also reported a significant relationship between the occupational status and the women's social cooperation. Therefore, the women's demographic characteristics affect their cooperation.

With regard to the level of the knowledge and women's awareness, the results showed that most women barely knew about their rights and the potential areas of cooperation. The reasons might be believe in the masculine nature of the relief activities, conflict between the activities of crisis management and issues related to the family and children, believe in lack of support from the authorities and the managers as a motive for more women's participation in the natural disasters, and believe in not using the research and the consequent results related to women in crisis management programs. The results also indicated that there was a significant relationship between the knowledge and the level of the cooperation and also between the women's attitude and their cooper- 
ation. Therefore, the third and the forth hypotheses were also confirmed. Vosoughi and Yousefi Aghabin (2005) also concluded that there was a significant relationship between the women's attitude toward themselves and their social cooperation.

\section{Conclusion}

In general, our study results showed that despite the large number of women and their talents and potential in society as well as experience of earthquakes occurred in the country (such as Bam earthquake), women have little share in crisis management operations and only participated in some of the patients' nursing activities and taking care of the orphans. The reasons for this low cooperation can be attributed to their poor knowledge and the negative attitude of the patriarchal society toward the presence of women, especially in managing and planning activities. Participating women in educational issues, prevention, managing activities, and so on can pave the way to deepen and strengthen the safety culture among families. Women with regard to their influence on other groups of society can play an effective role in maintaining safety and empowering the families.

Moreover, the effective presence of women and their multiple roles after the accident can also represent the influential presence of women in reducing the vulnerability of the accidents. The results of such studies can provide the grounds for more studies and research in this area and help the related authorities to use women who can play an important and vital role in crisis management programs which needs the authorities' more attention. Finally, with regard to the different experiences of the earthquakes, especially in Bam in 2003, some recommendations are presented as follows:

- Increasing the awareness of related authorities to identify the various aspects of women's participation,

- Identifying women's abilities and increasing the awareness of the society about the earthquake,

- Encouraging women's activities in the prevention, planning, education, and organization before the accident,

- Collaboration with the relief staff, providing health services to women and children during crisis,

- Involving women in managerial positions and the activities of crisis management, and
- Using women in reconstruction process, providing statistics and information, health services, camp management, association, rehabilitation and relief and other measures in the post-crisis stage.

Regarding the study limitations, we can mention to the lack of previous related field studies in Iran, repeated travel to Bam to distribute the questionnaires and interviewing with authorities.

\section{Acknowledgements}

This study is part of the research entitled "Studying women's cooperation in natural disasters and accidents," approved by the Vice Chancellor for Research, Management of Kerman University of Medical Sciences and the country's Health Research Center.

\section{Conflict of Interest}

The authors declared no conflict of interests.

\section{References}

[1] Jahangiri K, Azin SA, Rahimi Foroushani A, Montazeri A. [Selective strategies of people in information seeking and public education to prepare for an earthquake: Exploring views and expectations of the people in Tehran city (Persian)] Payesh Quarterly. 2010; 10(1):49-54.

[2] Koolaee E, Hafezian M. [The role of women in the development of Islamic countries (Persian)]. Tehran: Tehran University Press; 2006

[3] Ministry of Labor, [women participation :sustainable solution for social problems (Persian)] [Internet]. 2011 [Cited 2011 December 15]. Available from: www.mcls.gov.ir/fa/search

[4] Zarvandi D. [The role of women in management of politicalsecurity crises (Persian)]. Women's Cultural-Defense Studies Quarterly. 2005; 1(3):71-92.

[5] Jones R. Gender and natural disaster: Points to ponder. Geneva: International Labour Organization. [Internet]. 2000 [Cited 2011 December 15]. Available from: http://natlex.ilo. ch/wcmsp5/groups/public/@ed_emp/@emp_ent/@ifp_ crisis/documents/publication/wcms_116391.pdf

[6] World Health Organization. Gender and health in disasters. Geneva: World Health Organization; 2002.

[7] World Health Organization. Gender and natural disasters. Geneva: World Health Organization; 2002.

[8] Zellerer E, Vyortkin D. Women's grassroots struggles for empowerment in the republic of Kazakhstan. Social Politics. 2004; 11(3):439-64. doi: 10.1093/sp/jxh044 
[9] Canadian Women Health Network. Women \& disaster [Internet]. 2010 [Cited 2010 Apr 8]. Available from: http:// www.cwhn.ca/en/node/43300

[10] Parsizadeh F. [A needs assessment of women's priorities after the earthquake (About earthquake of 12, December 2003) (Persian)]. Paper presented at: The $2^{\text {nd }}$ International Conference on Disaster Management, The Role of Technology in Reducing Vulnerability Caused by Earthquake; 2012 Sep 24-25; Tehran, Iran.

[11] Artati HK. Learning of women's role each phase of disaster management through communinty empowermmt: A case study of earhquake 2006 and Merapi Eruption (2010) in Yogyakarta. Paper presented at: Disaster Risk Management in East Asia and Pasifik, Distance Learning Seminar Series; 2011 July 28; Yogyakarta, Indonesia.

[12] Pincha Ch. Participation of women in the community based disaster prepradness programme [Internet]. 2009 [Cited 2009 May 14]. Available from: https://www.gdnonline. org/resources/Pincha_Participation_Women_CommunityBased_DRR.pdf

[13] Parsizadeh F, Falahi V. [Golestan province earthquake (Persian)]. International Institute of Seismology and Earthquake Engineering, Ardabil, No. 174; 2012.

[14] Sharifi R, Heidari M. [Women's role in dealing with crises caused by natural disasters with an emphasis on the capabilities of the Basiji Women (Persian)]. Zanan va Khanevadeh. 2004; 7(24):33-66.

[15] Ardalan A, Shamsi T. [Community-based disaster management guide based on the participation of women (Persian)]. Tehran: NGO for food collaborators/The World Health Organization, Islamic Republic of Iran; 2007. Available from: http://ssu.ac.ir/cms/fileadmin/user_upload/ Daneshkadaha/dbehdasht/salamat_dar_balaya/fileamozeshi/rahnamaye_cbdrm_mobtani_bar_zanan.pdf

[16] Ostovar Izadkhah Y. [Women and natural disasters: Vulnerable in accidents or capable of managing the crisis (Persian)]. Journal of Rescue \& Relief. 2010; 2(2):71-80.

[17] Yazdanpanah L, Samadian F. [The effect of personal and social characteristics on the social participation of women in Kerman (Persian)]. Journal of Women's Studies. 2008; 6(2):127-49.

[18] Kurdi H. [Factors affecting the attitude of women on social participation in Golestan province (Persian)]. Journal of Peyke-Noor. 2007; 5(1):7-25.

[19] Safiri Kh. [Women and higher education (Persian)]. Journal of Social Issues. 2006; 56(56, 57):101-27.

[20] Qureshi F, Alizadeh Aghdam MB, Ibrahimi Torkamani A. [Factors affecting social participation of women over 20 years, Tabriz city (Persian)]. Economic Sociology and Development Quarterly. 2012; 1(2):115-41.

[21] Ghaderzadeh O, Yousefvand H. [Sociological factors affecting civic participation of women (Persian)]. Women in Development \& Politics. 2011; 10(4):101-26.

[22] Vosoughi F, Yousefi Aghabin A. [Sociological research in the field of social participation of rural women of Aghkand, Mianeh city (Persian)]. Quarterly Journal of Social Sciences Letter. 2005; 25(2):195-224. 